\title{
Oxygen-ozone therapy in a multidisciplinary day surgery: Design and applications
}

\author{
Paolo Barone \\ Anesthesiology and Intensive Care Department, S. Anna-Como Hospital, Como, Italy
}

\begin{abstract}
Oxygen-ozone therapy is an increasingly widespread practice for its multiple applications, supported by data and specialized scientific literature. For this reason, an increasing number of hospital companies are showing considerable interest in order to expand the range of therapies provided. A feasibility study has been carried out with application models, with particular attention to the specialist sectors present in the San Fermo della Battaglia - S. Anna-Como Hospital, Italy.
\end{abstract}

\section{Introduction}

This paper, after a brief description of ozone and its therapeutic properties, evaluates the operational opportunity to use oxygen-ozone therapy within the facility of multidisciplinary day surgery (DS) located in the Larian Territorial Health Company S. Anna-Como Hospital, where the writer works.

The feasibility analysis covers both the operational context and the strictly professional health care environment.

The following is a logistical and organizational description of the operational unit of multidisciplinary DS and of the main pathologies that persist in it, potentially treatable by oxygenozone.

Correspondence: Paolo Barone, Anesthesiology and Intensive Care Department, S. Anna-Como Hospital, Como, Italy.

E-mail: paolo.barone@asst-lariana.it

Key words: Oxygen-ozone therapy; Multidisciplinary day surgery; Design; Applications.

Received for publication: 11 September 2017.

Accepted for publication: 20 September 2017.

(C) Copyright P. Barone, 2017

Licensee PAGEPress, Italy

Ozone Therapy 2017; 2:7081

doi:10.4081/ozone.2017.7081

This article is distributed under the terms of the Creative Commons Attribution Noncommercial License (by-nc 4.0) which permits any noncommercial use, distribution, and reproduction in any medium, provided the original author(s) and source are credited.

\section{Ozone and its therapeutic properties}

\section{What is ozone?}

Ozone $\left(\mathrm{O}_{3}\right)$ is a compound made up of three oxygen atoms willing to form a hybrid resonance; this peculiar chemical structure explains the high reactivity of the molecule and its behavior at the biological level.<smiles>[O-][O+]=[Os]</smiles>

I<smiles>O=[O+][O-]</smiles>

II

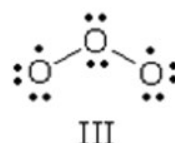

III
The unstable allotropic form of ozone (i.e. the property of existing in different chemical forms) tends to transform it, under certain conditions, into biatomic oxygen $\left(\mathrm{O}_{2}\right)$. Two oxygen atoms form the basic molecule, while the third oxygen atom can detach from the ozone molecule and interact with molecules of other substances. In addition to being present in the earth's atmosphere, ozone, thanks to its high oxidizing power, is used as a bleaching agent, disinfectant and in water purification. Medical ozone, on the other hand, is produced by specific generators that use a flow of pure oxygen that is subjected to a Voltage difference between 5,000 and 15,000 volts; this procedure is able to separate the molecules of $\mathrm{O}_{2}$ always present in excess forming the ozone molecules $\left(\mathrm{O}_{3}\right)$.

\section{Oxygen-ozone therapy}

Oxygen-ozone therapy is a technique applied in the medical field that uses a mixture of oxygen gas $\left(\mathrm{O}_{2}\right)$ and ozone $\left(\mathrm{O}_{3}\right)$ in varying proportions for therapeutic purposes.

The first applications of ozone date back to 1856, just 16 years after its discovery, used as a disinfectant for operating theaters and to sterilize surgical instruments. In 1892, an article was published describing the administration of ozone for the treatment of tuberculosis. During World War I, doctors used it to treat wounds, trench feet and the effects of poisonous gases. ${ }^{1}$

\section{Contraindications and side effects}

The only definite contraindications to the application of this technique are established clinical hyperthyroidism and favism. Effects on the fetus are not yet documented, but like many other therapies, they are not practiced in pregnancy.

Side effects other than coughing caused by accidental inhalation of the mixture are not described, as ozone has an irritating effect on the airways. ${ }^{2}$

\section{Administration}

The routes of administration of the therapeutic mixture are manifold and depend on the pathology: subcutaneous; intramuscu- 
lar; intrarticular; insufflative (anal, vaginal, uterine, urethral, joint); topical; hydropinic; minor autohemoinfusion; major autohemoinfusion. ${ }^{3}$

\section{Mechanism of action}

Ozone, together with reactive oxygen forms such as superoxide, singular oxygen, hydrogen peroxide and hypochlorite ions, is naturally produced by white blood cells and other biological systems as a means of destroying foreign bodies. Ozone reacts directly with double organic bonds, disturbing them to neutralize the invading agent.

Griegge's ozonolysis mechanism of unsaturated organic substances demonstrates the formation of peroxides and aldehyde groups: ozone reacts especially with biological liquids both intra and extra cellular. The complexity of the biochemical reactions generated during blood exposure to ozone involves, in the space of microseconds, a very wide range of substrates that interact in different metabolic pathways.

Among biological liquids, the substrates with which ozone preferably reacts are unsaturated fatty acids (PUFAs). By intervening in the breakage of the bonds between the latter and the red blood cells, ozone gives rise to more stable species [lipid oxydation products (LOPs)] that improve the oxygen transport performance and consequently the microcirculation.

Ozone, being an unstable molecule, determines oxidative reactions generating a calculated and transitory oxidative stress that stimulates the intracellular antioxidant system. ${ }^{4}$

\section{Clinical indications}

The Scientific Society of Oxygen Ozone Therapy (SIOOT) provides the main clinical indications of the use of ozone with fungicide, antibacterial, viral inactivation, analgesic, anti-inflammatory, immunomodulant, antioxidant, circulatory activator, increased stress resistance, anti-age action. The clinical indications are summarized in Table 1.

Table 1. Oxygen-ozone therapies: clinical indications.

\begin{tabular}{|c|c|}
\hline Neurosurgery & $\begin{array}{l}\text { Discal hernia; } \\
\text { Post-operative pain from spinal surgery; } \\
\text { Lumbar sciatica }\end{array}$ \\
\hline Angiology and Phlebology & $\begin{array}{l}\text { Venous insufficiency; } \\
\text { Diabetic ulcer; } \\
\text { Post-flebitic ulcer; } \\
\text { Peripheral arteriopathy }\end{array}$ \\
\hline Rheumatology and Orthopedics & $\begin{array}{l}\text { Joint rheumatism; } \\
\text { Low back pain; } \\
\text { Gonarthrosis; } \\
\text { Collagen vascular disease; } \\
\text { Fibromyalgia }\end{array}$ \\
\hline Internal Medicine & $\begin{array}{l}\text { Hepatitis; } \\
\text { Crohn disease; } \\
\text { Ischemic cardiopathy; } \\
\text { After stroke recovery }\end{array}$ \\
\hline Nephrology and Dialysis & Adjuvant in the treatment of ischemic metabolic osteoarticular pathologies concomitant with long duration treatment \\
\hline Neurology & $\begin{array}{l}\text { Cluster headache; } \\
\text { Depression; } \\
\text { Neurovascular diseases; } \\
\text { Chronic fatigue syndrome }\end{array}$ \\
\hline Dentistry & $\begin{array}{l}\text { Dental caries and e post-surgery disinfection; } \\
\text { Osteonecrosis of the jaw caused by bisphosphonates }\end{array}$ \\
\hline Oncology & Adjuvant in radiotherapy or chemotherapy due to increase of the interstitial $\mathrm{pO}_{2}$ of neoplastic tissue \\
\hline Ophthalmology & Degenerative maculopathy \\
\hline Degenerative diseases & $\begin{array}{l}\text { Early senile dementia; } \\
\text { Multiple sclerosis; } \\
\text { Amyotrophic lateral sclerosis; } \\
\text { Parkinson's disease }\end{array}$ \\
\hline Gynecology/Urology & $\begin{array}{l}\text { Infections of the vagina and uterus; } \\
\text { Urethritis; } \\
\text { Perineal infections }\end{array}$ \\
\hline Intestinal dysbiosis & $\begin{array}{l}\text { Irritable bowel; } \\
\text { Food intolerance; } \\
\text { Constipation; } \\
\text { Gastric ulcer; } \\
\text { Helicobacter pilori }\end{array}$ \\
\hline Dermatology & $\begin{array}{l}\text { Herpes Zoster and Simplex; } \\
\text { Acne; } \\
\text { Eczema; } \\
\text { Lipodystrophy (cellulite); } \\
\text { Esthetic medicine }\end{array}$ \\
\hline
\end{tabular}


As can be easily assumed, many of the applications described above could be carried out under the multidisciplinary DS regime.

The purpose of this thesis is to assess the appropriateness of organizing and regulating the application of oxygen-ozone therapy in a day hospital unit. ${ }^{5-7}$

\section{Oxygen-ozone therapy in multidisciplinary day surgery}

Description of the multidisciplinary day surgery of San Fermo della Battaglia - S. Anna-Como Hospital, Italy

The multidisciplinary day surgery of San Fermo della Battaglia - S. Anna-Como Hospital was founded as an autonomous entity in October 2010, following the transfer of the entire hospital to the current location. At the same time, the mission of the hospital structure changed and, in agreement with Lombardy Region, it was transformed into a structure modulated for intensity of care and continuity assistance. The new organization has provided for the disappearance of the operational units meant as separate and independent wards, while within the same hospitalization spaces, areas of equal surgical and/or internal intensity have been merged.

Today, the DS is expressed with the presence of 27 beds plus an armchairs area dedicated to eye care. Inside there are: 4 visit rooms, 2 nursing rooms, 1 osteomate-assistance room, head office, common areas.

The operational units that insist on the DS are 12 and more precisely: Urology, Gynaecology, General Surgery, Vascular Surgery, Thoracic Surgery, Orthopaedics, Neurosurgery, Plastic Surgery, Otorinolaryngology, Maxillofacial Surgery, Oculistics, Anesthesia (Antalgic Therapy).

DS business volume averages around 5500 persons/year.

Patient selection, in order to express the suitability for a DS procedure, is carried out by means of a pre-housing, which has an overall activity volume of approximately 9000 persons/year.

Both the Surgeon and DS are managed by the same physician in charge of the Operating Unit of the Anaesthesia and Resuscitation Complex.

Obviously, not all patients accessing DS are candidates for possible oxygen-ozone therapies, but also many of the patients admitted to normal hospitalization in the various areas of stay could benefit from the therapy under examination.

Below is a map of the operational units plan of DS inserted in the ground floor of the S. Anna-Como Hospital and a detail of the DS itself (Figures 1 and 2).

\section{Oxygen-ozone centralized therapy}

What above said determines the opportunity to consider a centralized activity, within the DS for the administration of oxygenozone therapy in pathologies to varied genesis.

The multidisciplinarity already experienced, also from the point of view of care by the permanent nursing team, represents the added value for an expert, effective and economic approach so that this activity can be expressed at high levels.

\section{Work-flow}

The work-flow suitable for optimizing the activity in question involves the various steps shown in Figure 3.

The first step is obviously the recruitment of the patient who could benefit from oxygen-ozone therapy, which can take place through the usual channels of access to the hospital: pre-housing, reservation center and hospitalization areas that indicate the birth of the needs.

The patient is then evaluated by the ozonotherapist, together with the branch specialist for the planning of the therapeutic intervention. Afterwards, the patient is described the chosen method, which starts immediately after he/she signs the informed consent. From the beginning of the therapy, interim assessments are periodically carried out to validate the existing path or to implement therapeutic corrections.

The end point is the healing state or marked clinical improvement of the the patient that allows him/her to be released from the therapeutic line or a pro tempore suspension of the same.

At present, the hypothesis of using a reserved area within the DS to carry out this therapy could be expressed in two days/week, considering both the workload and the scheduling foreseen by the SIOOT protocols. Within the existing DS organization, these days could be held on Mondays and Thursdays.

The activity would be carried out by a single anesthetist-reanimator physician with ozonotherapist qualification, acquired

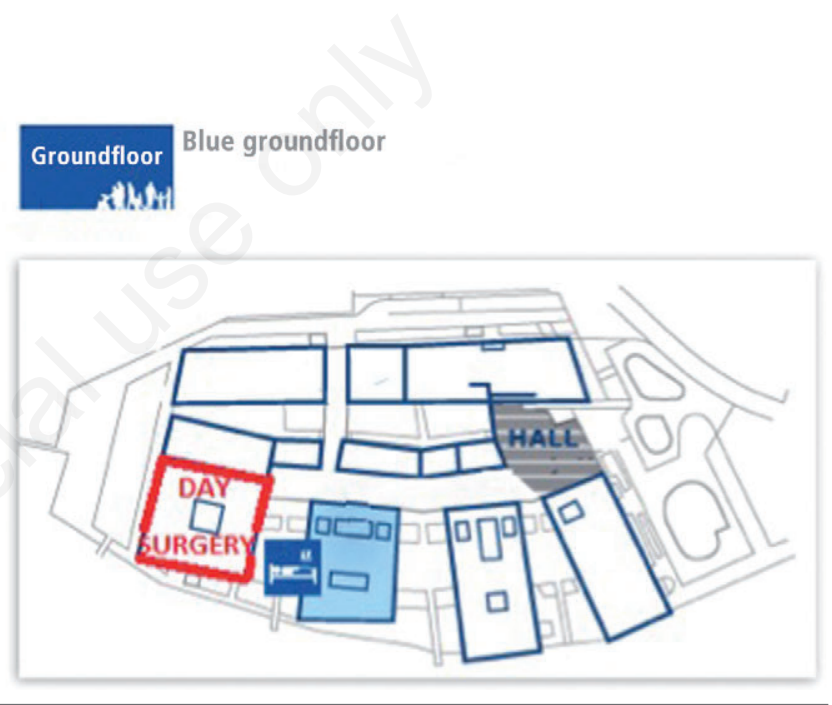

Figure 1. Planimetric map of the day surgery unit located on the groundfloor of the S. Anna-Como Hospital, Italy.

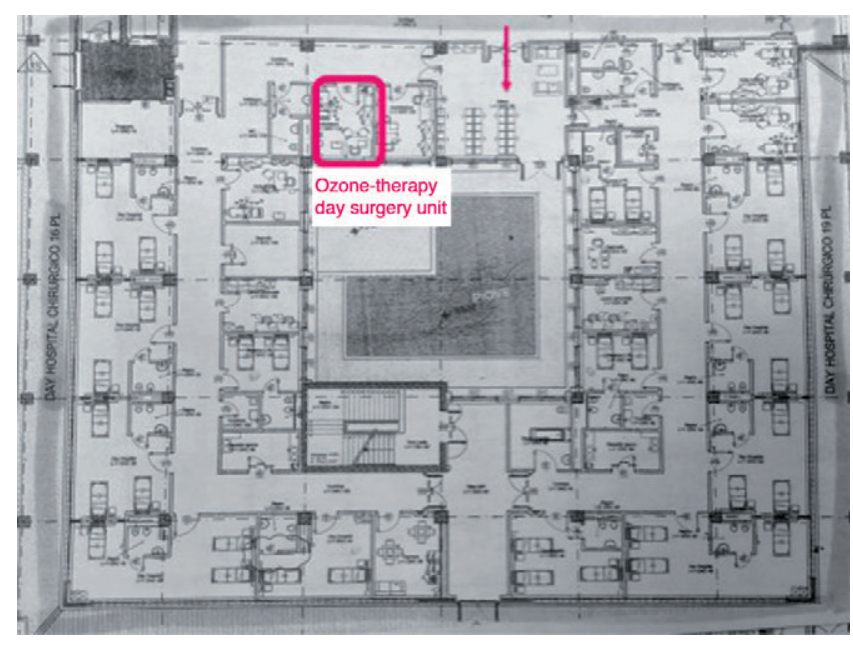

Figure 2. Detail of the planimetric map of the day surgery unit. 
through a Master's Degree in Oxygen-Ozone Therapy at the University of Pavia, Italy.

At the time of writing of this work and on an experimental basis, an activity has already been started within the DS, aimed at verifying the feasibility of the working hypotheses formulated.

The therapeutic applications described below are the result of this preliminary trial.

First examination, simple infiltrative procedures, infiltrative procedures with self-hemoinfusion insufflation/minor, major autohemoinfusion, with no more than 15 patients.

In the case of direct DS access, the timing assessment varies according to first examination, simple infiltrative procedures, infiltrative procedures with insufflations/minor autohemoinfusion, major autohemoinfusion, with no more than 15 patients.

\section{Investment program}

To start up the centralized activity, it is necessary to enter an investment program, compatible with the normal budgets available to hospital companies.

This obviously includes the purchase of instruments (oxygenozone generator) and of some devices for use. Figure 4 summarizes the necessary investments. Figure 5 shows the equipment currently available at S. Anna-Como Hospital.

\section{Procedures under the convention regime}

Currently, Lombardy Region offers the possibility to carry out only some ozone therapy procedures under the convention regime, namely: infiltration of therapeutic substances in the joint or ligament (Cod. 81.92, 27.90 EUR refund/session, max 8 sessions on prescription); injection of oxygen-ozone injection with photometric control (Cod. 92961, 18.45 EUR refund/session, max 6 sessions on prescription); oxygen-ozone in local bag (Cod. 93962, 7.90 EUR refund/session, max 6 sessions on prescription); oxygen-ozone almost total body (Cod. 93963, 13.15 EUR

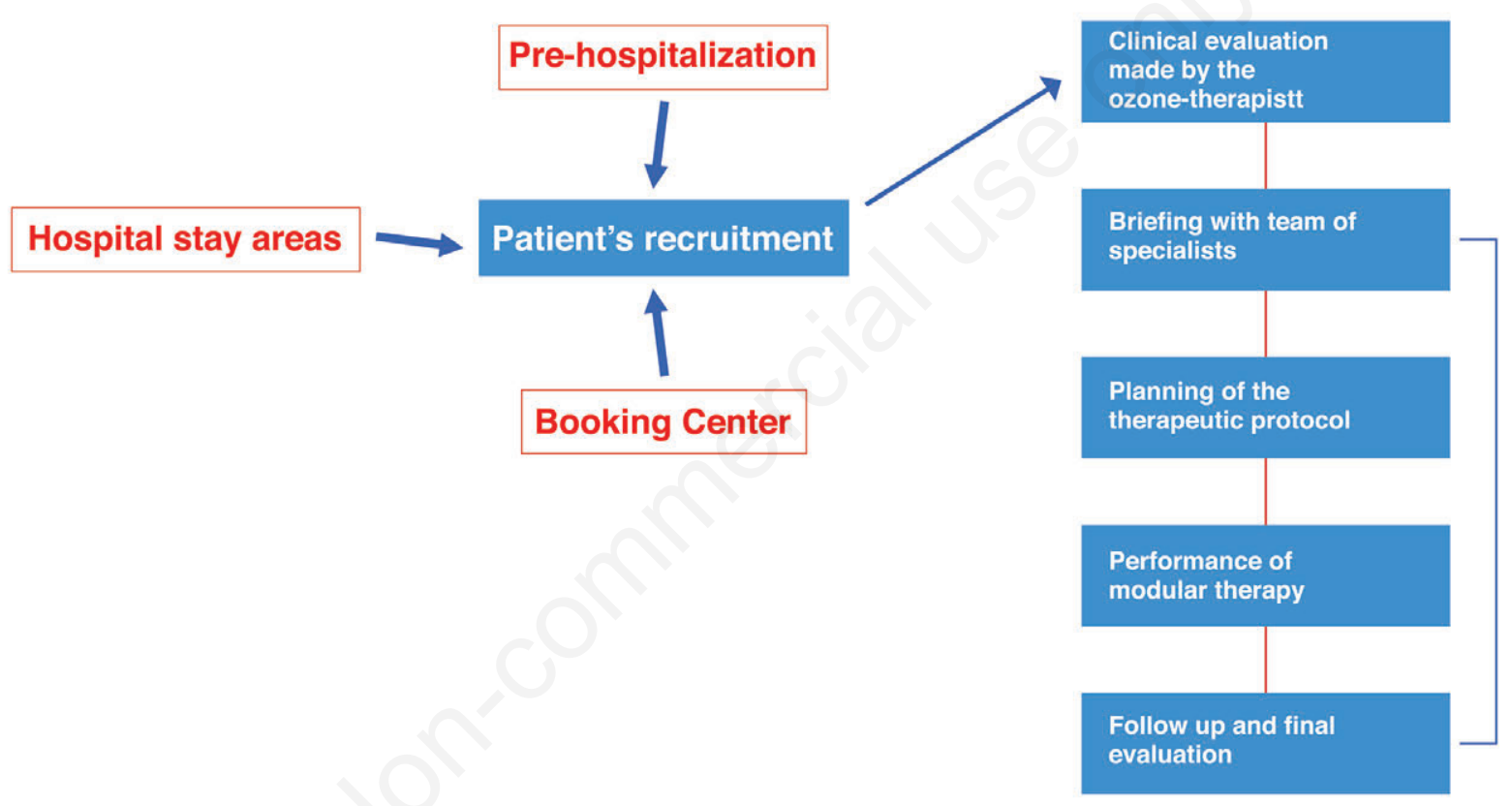

Figure 3. Work-flow suitable for optimizing the activity in question, which encompasses several steps.

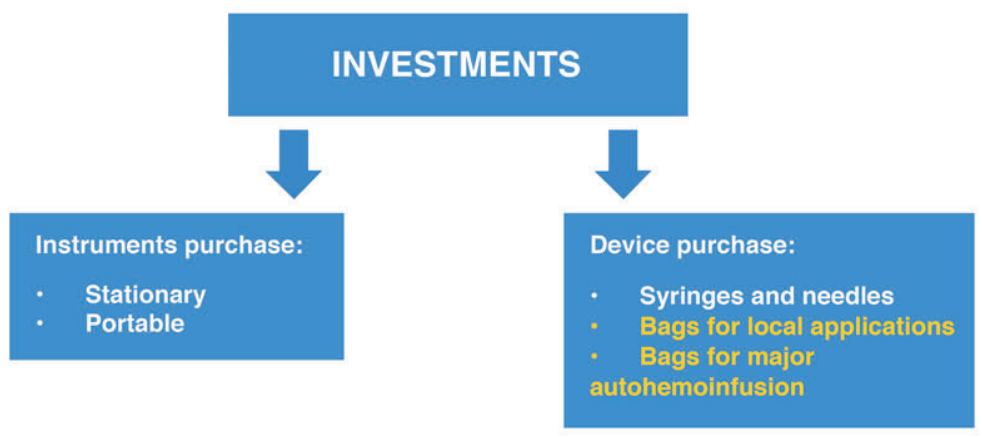

Figure 4. Summary of the necessary investments: only the facilities written in yellow are not currently available at S. Anna-Como Hospital, Italy. 
refund/session, max 6 sessions on prescription). All other procedures potentially applicable in the facility, to which reference is made below, should be practiced in the framework of intramoenia self-employment.

\section{Main applications and procedures used in day surgery}

Among the main pathologies that benefit from treatment in DS by oxygen-ozone therapy, there are cardiovascular diseases, especially those with peripheral expression, such as chronic obstructive arteriopathy, ulcers, chronic venous insufficiency.

Very often these manifestations present as comorbidities of the diabetic disease, which is an aggravating agent dangerous for the deposits of atherosclerotic material inside the vessels. The risk results to be both mechanical-obstructive and phlogistic with repercussions also on the microcirculation, such that the peripheral districts involved face a reduction in perfusion, reduction of tissue oxygenation, ischemia, necrosis.

The recruitment of most of the cases in this sector is carried out through the hospitalization in the Vascular Surgery Unit or through the Day Hospital in Diabetology Unit.

Applications in this field include perilesional infiltration techniques with a $26 \mathrm{G}$ insulin needle, using oxygen-ozone in a concentration of 5-10 g.

Since these lesions are extremely painful (NRS $>7$ ) even in non-operational phase, it is very advantageous to treat the affected area with topical application of eutectic mixture of local anesthetics 20 minutes before treatment begins. This enables the patient to achieve full compliance with the requirements of the patient, thus achieving an optimal level of operation.

Equally useful is the treatment not by infiltration technique but by the use of bags covering the lesion inside and where the oxygen-ozone mixture is placed.

Below is an image relating to the clinical case of a patient aged 78 years, suffering from peripheral arteriopathy and diabetic disease with serious deep ulcerative lesions with extensive areas of necrosis: the comparison between the photos shows a marked improvement in perfusion and reduction of necrotic areas after only 4 treatments of oxygen-ozone therapy by infiltrative technique with needle $30 \mathrm{G} 4 \mathrm{~mm}$ (Figure 6).
Other pathologies for which oxygen-ozone therapy application in DS is frequent and beneficial are hernias and discal protrusions. This technique allows to dry the hernia, reduce local inflammation, reduce paravertebral muscular contracture, allowing to intervene also on hernias already undergoing surgical treatment. Moreover, the antalgic action that appears to be present after the second application (on average 15 are expected) should not be underestimated. The degree of patient satisfaction is very high, as surgical treatment can be avoided in almost all cases. Similarly, by the healthcare structure, due to the reduction of hospitalization costs.

Shoulder, elbow and hand disorders can be easily treated in DS: the most frequent forms of shoulder are acromio-clavicular problems, scapulo-humeral periarthritis, inflammation of the rotator cuff. An elective treatment is obtained on the elbow in case of olecranon bursitis. For the hand and wrist, the carpal tunnel and Dupuytren's disease in the early stages.

In the orthopaedic field, prosthetic treatment of the hip and knee can cause periprosthetic infectious diseases. In such situations, conventional antibiotic therapy is too long as and may sometimes be ineffective and not conclusive, requiring recurring surgical interventions. Oxygen-ozone therapy, by means of periprosthetic infiltration technique assisted by major autohemoinfusion, offers a much more effective possibility of action by the antibiotic which, together with the gaseous mixture, is able to penetrate into the areas affected by the inflammation due to the effect of greater oxygen release and activation of microcirculation.

In the rheumatological field there are considerable possibilities of success of the therapeutic treatment under examination, in terms of improvement of the patient's quality of life, in pathologies such as rheumatoid arthritis, psoriasic arthritis, Sjogren's syndrome and in many autoimmune pathologies, because the oxygen-ozone mixture behaves as a hormetic (depending on the concentration used, i.e. it can act both as a stimulant and an inhibitor). In fact, ozormesis occurs when low doses of ozone stimulate the mitochondrial antioxidant system (while high doses would inactivate it).

Further possible collaboration would be desirable both with the Oncology Unit and the Neurology Unit. In the first case it would tend to improve the quality of life of the oncological patient, reduc-

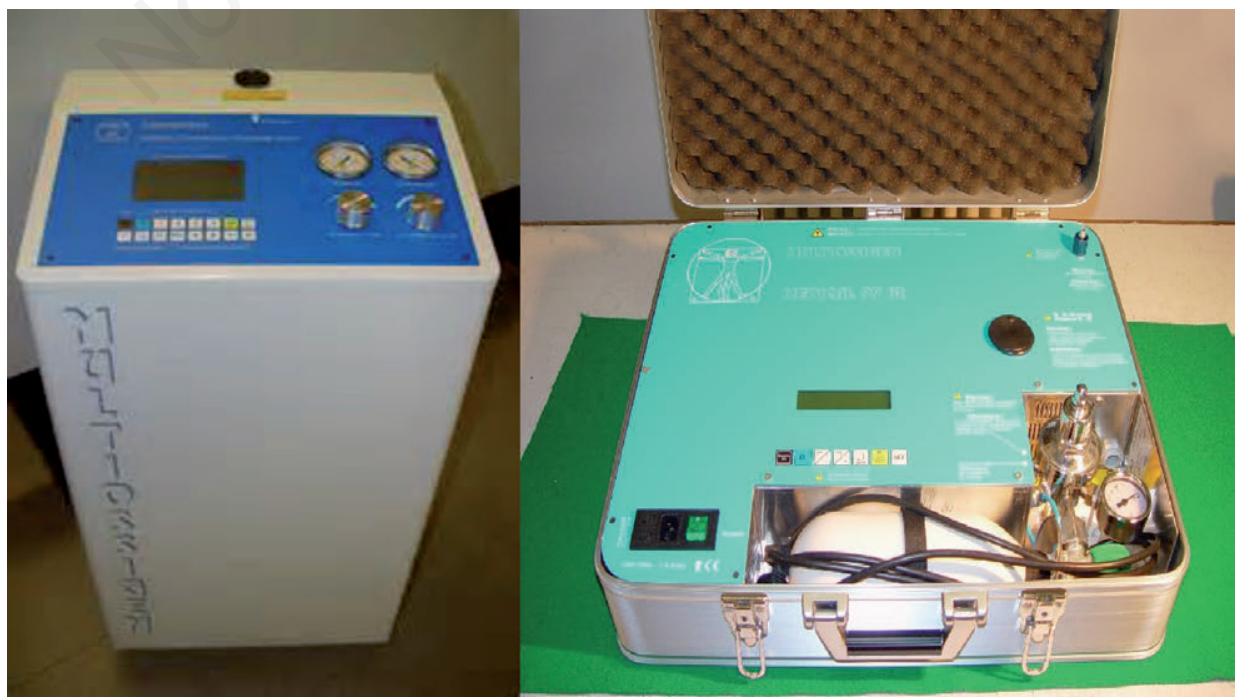

Figure 5. The equipment currently available at S. Anna-Como Hospital, Italy: left as fixed position, right as portable version. 

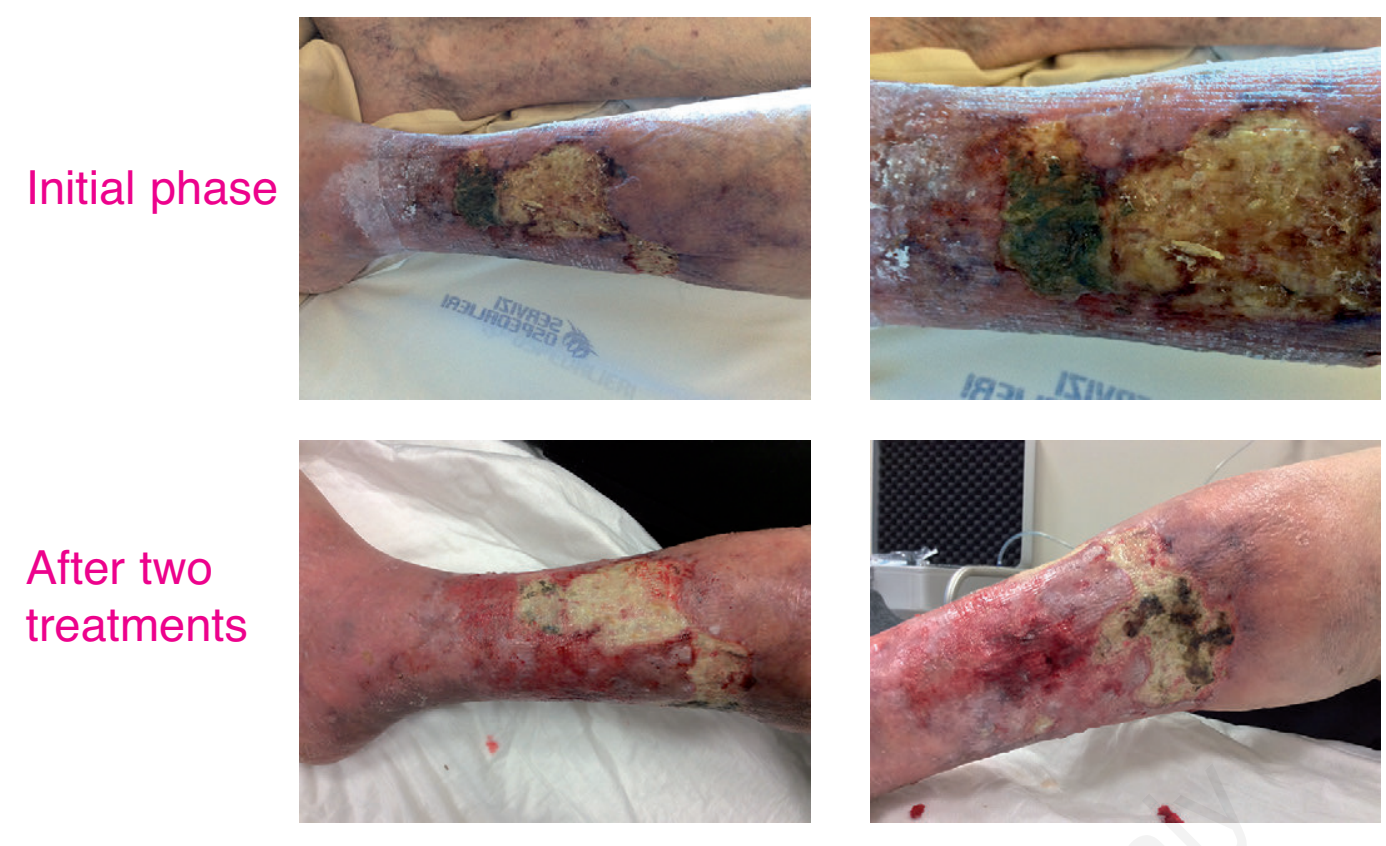

\section{After four treatments}
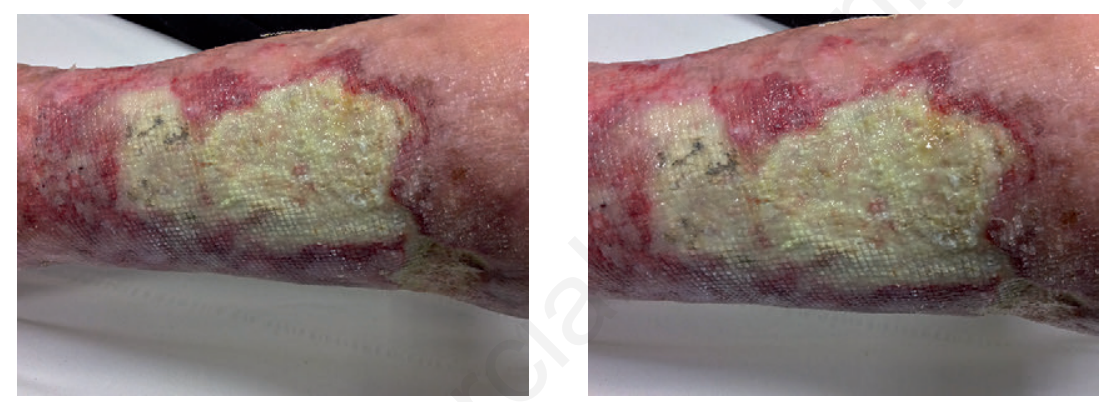

Figure 6. Iconography of a patient aged 78 years, suffering from peripheral arteriopathy and diabetic disease with severe deep ulcerative lesions with extensive areas of necrosis: the comparison between the photos shows a marked improvement in perfusion and reduction of necrotic areas.

ing the side effects of chemotherapy and radio therapy; in the second case it could help the treatment of cerebrovascular and neurodegenerative pathologies, where the use of oxygen-ozone therapy has already demonstrated significant results in terms of patient's cognitive recovery. ${ }^{8-11}$

\section{Conclusions}

The results of this preliminary assessment on the advisability of inserting an oxygen-ozone therapy clinic in a multi-disciplinary hospital DS show that, with no structural changes and extremely limited investments, high quality performance can be achieved. The advantages that can be obtained both from a clinical point of view in the evolution of pathologies and from an economic point of view in the overall reduction of hospitalization and care costs, even in the non-hospital phase, are overwhelmingly conclusive.

The activities already started in the experimental phase within the multidisciplinary DS of the S. Anna-Como Hospital, received considerable support both from the hospital units already and potentially involved.

The multiple possibilities of application and the variability of treatment techniques have aroused interest and collaboration among the various professional figures involved, suggesting an extremely participatory evolution.

A more appropriate evaluation can be carried out in the medium term ( 1 year from the start of the trial), through multiple systems that will have to take into account both the economic and patient satisfaction aspects through, for example, customer satisfaction questionnaires.

\section{References}

1. Bocci V, Aldinucci D, Borrelli E, et al. Ozone in medicine, Ozone Sci Engin 2001;23:207-17.

2. Bocci V. Scientific and medical aspects of ozone therapy. State of the art. Archi Med Res 2006;37:425-35.

3. Bonforte G, Bellasi A, Riva H, et al. Ozone therapy: a potential adjunct approach to lower urinary tract infection? A case series report. G. Ital. Nefrol. 2013;30:4.

4. Calabrese EJ, Baldwin LA. Hormesis: U-shaped dose responsis and their centrality in tossicology. Trend Pharmacol. Sci. 2001;22:285-91. 
5. Elvis AM, Ekta JS. Ozone therapy. A clinical review. J. Nat. Sci Biol. Med. 2011;2:66-70.

6. Franzini M. Le sindromi geriatriche e l'ossigeno-ozono terapia. Gorle (BG): SIOOT ed.; 2012.

7. Franzini M. Ossigeno ozono terapia. Cosa è e cosa fa. Manuale della buona salute senza dolore. Gorle (BG): SIOOT ed.; 2014.

8. Lintas G. Long-term cerebrovascular reactivity mediated by ozone autohemo therapy: a NIRS study. GNB 2012, June 26th29th, Rome, Italy.
9. Lipsky BA. Medical treatment of diabetic foot infection. Clin. Infect. Dis. 2004;39:104-14.

10. Paoloni M, Di Sante L, Cacchio A, et al. Intramuscolar oxigenozone therapy in the treatment of acute back pain with lumbar disc herniation: a multicenter, randomized, double-blind, clinical trial of active and simulated lumbar paravertebral injection. Spine 2009;34:1337-44.

11. Valdenassi L, Richelmi P, Bignamini A, et al. L'ossigenoozono terapia nell'insufficienza venosa cronica: studio clinico di efficacia e tollerabilità. Flebologia 1995;6:2. 